\title{
Lifestyle and Nutritional Risk in Women With Cervical Cancer: A Comparative Study
}

\author{
Zohreh Yeganeh $^{1}{ }^{\circledR}$, Zohreh Sheikhan $^{2 *}$, Nourossadat Kariman ${ }^{3}$, Taraneh Esteki $^{4}$, Mahrokh Dolatian $^{3}$, \\ Zohreh Mahmoodi ${ }^{5}$, Fahimeh Kavossi ${ }^{6}$
}

\begin{abstract}
Objectives: Cervical cancer can be prevented by identifying the lifestyle and diet. The purpose of this research was to compare lifestyle and nutritional risk in Iranian women with cervical cancer and healthy women who referred to hospitals affiliated to Shahid Beheshti University of Medical Sciences, Tehran, Iran during 2015-2016.

Materials and Methods: This descriptive-comparative study was conducted on 120 women referring to hospitals of Shahid Beheshti University of Medical Sciences, Tehran, Iran during 2015-2016. The data collection tool was a questionnaire that covered data on health-promoting lifestyle profile (HPLP), diet, and demographic characteristics. Finally, data were analyzed by SPSS software, using an independent $t$ test, as well as chi-square and Mann-Whitney tests.

Results: Statistical differences were observed between the number of delivery, smoking, and the smoking of the spouse although the difference in HPLP between the 2 groups was insignificant. However, healthy women could better manage their stress and interpersonal relations compared to women who had cervical cancer. As regards diet, fat was statistically different between the two groups $(P<0.05)$.

Conclusions: In general, a change in lifestyle, diet, reduced smoking can decrease the incidence of cervical cancer in women.

Keywords: Cancer cervix, Lifestyle, Nutritional risk
\end{abstract}

\section{Introduction}

Cancer is the third leading cause of death in Iran while this position belongs to cervical cancer in the United States. Based on previous data, 15 million people are diagnosed with cancer, 12 million of whom will die by 2020 (1). As mentioned, cancer is the third main cause of death in Iran with 300000 people killed annually (2). About $84 \%$ of cancers are reported in less developed regions (3). In 2012, cervical cancer was the 11th cause of cancers in women (9.9 per 100000) and the 9th cause of cancer deaths $(8.3$ per 100000) in developed countries (4). In Iran, the prevalence of cervical cancer was 2.17 per 100000 cases in 2009, ranking 11th among Iranian women's cancers (2). Cervical cancer treatment has significant side effects on the physical, sexual, and reproductive aspects of women. Most gynecologic cancers occur in women of older ages while cervical cancer engages young women (5). Only $5 \%-10 \%$ of cancers have a genetic origin (6) whereas $90 \%$ $95 \%$ of them are due to environmental and lifestyle factors (7). According to the estimations of the World Health Organization (WHO), $70 \%-80 \%$ of the mortality rate in developed countries is due to lifestyle changes and it anticipates that lifestyle changes cause 7 out of 10 deaths in developing countries by 2020 (8). In addition, more than $70 \%$ of the illnesses are caused by non-communicable diseases by 2026 in Iran and lifestyle is believed to have a special role in this regard (9). Although the pathogenicity of human papillomavirus (HPV) is proven in cervical cancer, especially HPV 16 and 18, it is insufficient and the lifestyle of women exposed to HPV can facilitate or control the effects of the virus. Sexual transmission is the most common way of virus transmission (10). It is noteworthy that the virus can be early detected and diagnosed through screening programs (11) and changing the lifestyle increases life expectancy in cancer survivors. (12). A limited number of studies have evaluated the lifestyle of gynecologic cancer survivors. (13-15). Increased cigarette smoking is observed in young women with cervical cancer (16). On the other hand, lifestyle is a way to provide, maintain, and improve health (8) thus cancer can be largely prevented by lifestyle modification (17). Today, by moving from a treatment approach to disease prevention, the WHO emphasizes the importance of promoting health and one of its components, namely, changing to a healthy lifestyle (18). A healthy lifestyle controls health costs, increases the quality of life, and reduces the burden

${ }^{1}$ Student Research Committee, Department of Midwifery and Reproductive Health, School of Nursing and Midwifery, Shahid Beheshti University of Medical Sciences, Tehran, Iran. ${ }^{2}$ Midwifery and Reproductive Health Research Center, Department of Midwifery and Reproductive Health, School of Nursing and Midwifery, Shahid Beheshti University of Medical Sciences, Tehran, Iran. ${ }^{3}$ Department of Midwifery and Reproductive Health, School of Nursing and Midwifery, Shahid Beheshti University of Medical Sciences, Tehran, Iran. ${ }^{4}$ Department of Nutrition, School of Nursing and Midwifery, Shahid Beheshti University of Medical Sciences, Tehran, Iran. ${ }^{5}$ Social Determinants of Health Research Center, Alborz University of Medical Sciences, Karaj, Iran. ${ }^{6}$ Islamic Azad University, Tehran, Iran.

*Corresponding Author: Zohreh Sheikhan, Tel: +982188202512, Email: zsheikhan@sbmu.ac.ir 
of diseases (19). Nutrition is considered as one of the important environmental factors which is associated with cancer (20). Previous studies have shown that nutrition alone is responsible for $3 \%$ to $40 \%$ of all cancers $(21,22)$. Approximately $30 \%$ and $20 \%$ of cancers in developed and developing countries are caused by nutritional factors, respectively (23), and the role of nutrition in cancer prevention is evident. (24). Therefore, maintaining and improving nutrition style is essential for maintaining and improving health (25). Thus, it is essential to be familiar with lifestyle and nutrition habits for planning health and education programs in the field of cancer since cancer risk factors vary due to differences in lifestyle, climate, and the type of food which is available in different societies. In this study, the researchers sought to answer whether lifestyle and diet have any relationship with cervical cancer. To this end, this study aimed to compare the lifestyle and nutritional risk in women with cervical cancer and healthy women who attended the hospitals affiliated to Shahid Beheshti University of Medical Sciences in Tehran, Iran during 2016.

\section{Materials and Methods}

This descriptive-comparative study was conducted in hospitals affiliated to Shahid Beheshti University of Medical Sciences in Tehran, Iran between October 2015 and March 2016. The hospitals with oncology sections (i.e., Taleghani, Imam-Hossein, and Shohadaye-Tajrish Hospitals) were designated and the women who referred to these hospitals for cervical cancer treatment comprised the patient group. Further, healthy women (control group), referring to other clinics and meeting the inclusion criteria, were selected through the convenient sampling method. Eligible women presented to the above hospitals were selected for participation in the study, therefore, 120 women were divided into 2 equal groups of 60 each (the type I error $\alpha$ of 0.05 , the power value of $90 \%$, and the effect size of $60 \%$ ). After explaining the goals and obtaining written consent from the women, they were enrolled upon their willingness. The participating women were assured of the confidentiality of their data and were provided with further information, if necessary. Furthermore, women were free to participate and could leave the study at any time. The inclusion criteria were having Iranian nationality and having CIN1, CIN2, or approved cervical cancer by a gynecologist in the patient group. Women were excluded from the study if they were unwilling to participate or fill out an incomplete questionnaire. Based on the aim of the study a questionnaire was used to collect the required data. Moreover, the cervical cancer stage was extracted from the gynecological records of the patients. Initially, an instrument was applied to gather socio-demographic information from the woman and her spouse (44 questions). The second part, health promoting lifestyle profile (HPLP), developed by Walker and Hill-Polerecky (26), contained 52 items and each item was rated on a four-point response (never to always). This part covered health responsibility, physical activity, nutrition, spiritual growth, interpersonal relations, and stress management. The points of the statements in each domain were summed up to obtain the score of each domain and then the scores of all questions were added up to obtain the total score of the questionnaire. The Persian version of HPLP II was used in this study, the reliability and validity of which was confirmed by Mohammadi Zeidi et al (27). In addition, the validity and reliability of this form were assessed using the content validity and test-retest methods. The Cronbach alpha coefficient was $(\alpha=0.80)$ and the reliability was measured by test-retest with a one-week interval $(r=0.81)$. Further, the third part was the diet questionnaire with 93 questions, which was approved by the Research Institute for Endocrine Science, Shahid Beheshti University of Medical Sciences. This form contained all nutritional factors such as fruits, vegetables, fat, nut, meat, and the like which were scored on a 4-point scale from "per day, week, month, year, and not at all ranging from 4 to 0 ". Using concurrent validity and test-retest methods, the reliability was determined as $r=0.78$ and the Cronbach's Alpha coefficient was estimated at $\alpha=0.79$. The 2 groups were matched by age and the sampling place. Eventually, the obtained data were analyzed by the SPSS software (version 16) utilizing descriptive statistics, $t$ test, as well as Mann-Whitney and chi-square tests. The values of $P<0.05$ were considered statistically significant.

\section{Results}

The current study was conducted on 120 women, and their demographic data are presented in Table 1 . The mean age of women was $39.01 \pm 1.02$ and $38.73 \pm 1.31$ years in patient and healthy groups, respectively. Further, the mean age of the first intercourse in women was $18.10 \pm 7.80$ and 19.58 \pm 7.11 years in patient and healthy groups, respectively. In patient group, the level of education was high school diploma $(63.3 \%)$ and $50 \%$ of them were housewives and $53.3 \%$ of them had a normal vaginal delivery while in healthy group, women had university education (43.3\%), $41.7 \%$ of them were housewives, and $46.7 \%$ of these women had a normal vaginal delivery. Furthermore, the mean age of patients' spouses was $42.50 \pm 1.56,46.7 \%$ of them were employees, and $40 \%$ of these men had a high school education. Moreover, the mean age of healthy women's spouses was $40.93 \pm 1.50,56.7 \%$ of them were employees, and $50 \%$ of these men had a university education. As shown in Table 1, the number of delivery and smoking women and their spouses were significant in the two groups $(P<0.05)$. As regards the HPLP questionnaire, the mean score of HPLP was higher in healthy women as compared to patient women but it was not significantly different. Contrarily, a significant difference was found between the groups in terms of interpersonal relations and stress management $(P<0.05)$, the details of which 
Table 1. Distribution of Patient and Healthy Women and Her Spouse by Their Characteristics

\begin{tabular}{|c|c|c|c|c|}
\hline Variable & Patient Women & Healthy Women & Test & $P$ \\
\hline BMI & $25.90 \pm 3.63^{a}$ & $24.09 \pm 3.13^{\mathrm{a}}$ & $t$ test & 0.100 \\
\hline Age of marriage (y) & $20.70 \pm 4.60^{a}$ & $20.98 \pm 4.95^{\mathrm{a}}$ & $t$ test & 0.732 \\
\hline Number of delivery & $16.3 \pm 2.90$ & $2.11 \pm 1.60^{\mathrm{a}}$ & $t$ test & $0.014^{*}$ \\
\hline \multicolumn{5}{|l|}{ History of OCP } \\
\hline Yes & $34(56.7)$ & $33(55)^{b}$ & $\chi^{2}$ & 0.201 \\
\hline No & $26(43.3)$ & $27(45)$ & & \\
\hline \multicolumn{5}{|l|}{ History of IUD } \\
\hline Yes & $12(20)$ & $11(18.3)^{b}$ & $\chi^{2}$ & 0.110 \\
\hline No & $48(80)$ & 49(81.7) & & \\
\hline \multicolumn{5}{|l|}{ Smoking } \\
\hline Yes & $9(15)$ & $12(20)^{b}$ & $\chi 2$ & $0.000^{*}$ \\
\hline No & $51(85)$ & $48(80)$ & & \\
\hline \multicolumn{5}{|l|}{ Smoking spouse } \\
\hline Yes & $39(65)$ & $34(56.7)^{\mathrm{b}}$ & $\chi^{2}$ & $0.000^{*}$ \\
\hline No & $21(35)$ & $26(43.3)$ & & \\
\hline
\end{tabular}

BMI, Body mass index; OCP, oral contraceptive pill; IUD: Intrauterine device.

${ }^{\text {a } M e a n \pm S D ;}{ }^{\text {b }}$ No. $(\%) ;{ }^{*} P<0.05$.

are provided in Table 2. Regarding the diet section, fat consumption was significantly different $(P<0.05)$ between the 2 groups (Table 3 ).

\section{Discussion}

In this study, the number of delivery in patients was higher than that of healthy women. Similarly, Misra et al indicated that high childbirth plays a significant role in the distortion and transformation of cervical cells (28). Sreedevi et al showed that multiple pregnancies are considered as an epidemiological risk factor (29). It seems that extremely high levels of estrogen and progesterone in the blood, which are at their highest levels during pregnancy, change the bond between the squamous and

Table 2. Comparison of HPLP in 2 Groups of 60 Women

\begin{tabular}{|c|c|c|c|}
\hline Dimension of HPLP & Healthy Women (Mean Rank) & Patient Women (Mean Rank) & $P$ value \\
\hline Nutrition & 64.54 & 56.46 & $0.201^{\mathrm{a}}$ \\
\hline Physical activity & 66.52 & 54.48 & $0.057^{\mathrm{a}}$ \\
\hline Health responsibility & 61.62 & 59.38 & $0.722^{\mathrm{a}}$ \\
\hline Stress management & 68.16 & 52.84 & $0.015 a^{*}$ \\
\hline Interpersonal relations & 68.29 & 52.71 & $0.013 a^{*}$ \\
\hline Spiritual growth & 59.45 & 61.55 & $0.740^{\mathrm{a}}$ \\
\hline Total & $6.98 \pm 195.39$ & $6.32 \pm 182.77$ & $0.057^{\mathrm{b}}$ \\
\hline
\end{tabular}

HPLC, Health-promoting lifestyle profile.

${ }^{\mathrm{a}}$ Mann-Whitney test; ${ }^{\mathrm{b}} \mathrm{t}$ test.

Table 3. Comparison of Diet in 2 Groups

\begin{tabular}{|c|c|c|c|}
\hline Nutritional Components & Healthy Women (Mean \pm SD) & Patient Women (Mean \pm SD) & $P$ Value \\
\hline Cereals & $48.8 \pm 11.56$ & $47.31 \pm 12.12$ & $0.296^{a}$ \\
\hline Meat & $58.85 \pm 10.05$ & $63.21 \pm 9.41$ & $0.057^{a}$ \\
\hline Meat (fish and chicken) & $54.03 \pm 15.22$ & $56.11 \pm 14.38$ & $0.485^{a}$ \\
\hline Honey & $80.42 \pm 21.13$ & $80.41 \pm 19.03$ & $0.824^{a}$ \\
\hline Tea & $92.08 \pm 20.83$ & $91.66 \pm 19.88$ & $0.950^{\mathrm{a}}$ \\
\hline Spices & $86.66 \pm 20.82$ & $85.83 \pm 18.62$ & $0.576^{a}$ \\
\hline Pickles & $71.14 \pm 13.32$ & $66.77 \pm 10.94$ & $0.133^{\mathrm{a}}$ \\
\hline Oil & $52.58 \pm 13.40$ & $59.83 \pm 11.94$ & $0.047^{a^{*}}$ \\
\hline Vegetables & $67.29 \pm 7.70$ & $65.69 \pm 9.47$ & $0.546^{a}$ \\
\hline Cooked vegetables & $60.83 \pm 10.18$ & $58.85 \pm 10.15$ & $0.349^{a}$ \\
\hline
\end{tabular}

SD, Standard deviation.

a Mann-Whitney test. 
columnar epithelium cells (30). Additionally, Muñoz et al argued that epithelium eversion and the metaplasia of squamous epithelium are common during pregnancy and cervical ectropion causes the HPV to become more exposed and makes the person susceptible to cancer as well (31). In contrast, Anorlu found, men could have a role in the development of cervical cancer since the incidence of cervical cancer increases by an increase in the number of wives a man has based on several marriages (32). Our results demonstrated a relationship between smoking women and their spouses with cervical cancer. Likewise, Appleby et al concluded that the incidence of cervical cancer was higher in smoking patients (33). In addition, Gandini et al reported that smoking can both cause cancer and facilitate the development of cancer. However, scientists have not yet been able to explain this relationship (34). Cigarettes might be a cofactor of women's cancers, which works through thickening the cervical mucus (35). Smoking further decreases the immune response in cervical cells and may affect the metabolism of female hormones. One should also consider that genetic damage is directly related to tobacco carcinogenesis (36). The comparison of the dimension of lifestyle and stress management indicated a significant relationship between the two groups. The mean score of stress management in patients was lower compared to healthy women, which is in agreement with the result of the study by Reiter et al (35). Similarly, Oran et al discovered changes in HPLP is possible by increasing the awareness about the periodic screening of cancer, but this is not applicable to all women in the community. It is believed that stress changes the regularity of hormones which are secreted by the pituitary and hypothalamus (37). It causes emotional disorders such as anxiety and depression as well (38). Cancer diagnosis and treatment are associated with various stress and anxiety which worsen the disease severity in patients with cancer. High stress occasionally inhibits treatment or preventative behaviors (39). One of the most important factors affecting the mental status of cancer patients is how they cope with cancer-induced stresses. For instance, Pillay et al reported avoidance, disappointment, and frustration are likely to increase the recurrence of cancer (40). Moreover, Clemmens et al showed that the expression of excitement is associated with an increased likelihood of recovery in cancer patients (41). Likewise, You et al. reported that optimistic patients with cancer feel less pain and have a better performance in other areas of life (42). Sisolefsky et al also argued that the rate of recovery is lower in disappointed patients (43). Kapogiannis et al in their study found that the use of relaxation techniques reduces stress and anxiety in cancer patients (44). Additionally, relaxation is believed to reduce muscle tension and eliminate stress-induced undesirable physiological effects. In addition, relaxation techniques with a coping effect against stress decrease the activity of the sympathetic nervous system, as well as the secretion of the catecholamines (45). In the present study, there was a significant difference in interpersonal relations between the two groups, which is in line with the findings of Semple et al (46). Patients with cancer have some degrees of psychiatric and emotional disorders such as depression, anxiety, incompatibility with the disease, reduced selfconfidence, along with a fear of the recurrence of the disease and death (47). These patients exhibit a lower level of resilience and are prone to mental illness as well (48). The number of close friends and participation in social activities lead to an increase in hopeful thoughts and thus reduce mortality (49). Furthermore, hair loss and other changes caused by the disease and its treatment are among the causes of a change in patients' mood, which leads to their reduced communication. Cancer also alters patients' mental image. In other words, changes in the appearance alter the mental needs of many patients and lead to their little desire for communication. They may not make eye contact, do not carry out therapeutic and self-care recommendations, and show anger and aggression responses. In addition, the weakening of morale due to the knowledge of cancer diagnosis and its unpredictability is considered as a deterrent factor for communication (50). In diseases such as cancer that are associated with rapid progress and sudden changes, treatment might disrupt the psychosocial mechanisms of the patients and make them feel sad. In the acute phase of the disease, patients are dreaming of returning to their former lives, and they become anxious and depressed when they realize they are no longer able to achieve it (51). Therefore, this situation poses a significant impact on their communication interactions. Emotional support from the family, especially the spouse and friends, in cancer patients is associated with increased self-esteem and decreased distress and the feeling of vulnerability, which is achievable with effective communications (52). Regarding the diet dimension in this study, the researchers observed that the prevalence of the lipid diet of patients was higher than that of healthy women, which is in conformity with the results of Ulmer et al and Cust et al $(53,54)$. It is found that estrogens stimulate hepatic triglyceride secretion (55) and high serum triglyceride concentrations may also reflect plasma glucose levels. Further, hyperglycemia and Inflammation are the other potential mechanisms of hypertriglyceridemia $(58,59)$. Similarly, sexually transmitted globulin concentrations may be linked to colorectal cancer risk by bile acid excretion, circulation hormones, or energy supply to neoplastic cells (53). Lipid metabolism is involved in cancer cell biology as well. Furthermore, the synthesis of DNA and proteins along with the production of lipids is necessary for cell growth and proliferation. However, lipids are also active players in signaling processes that are involved in cell transformation and tumor development. Lipids cause cellular hypoxia, and cell proliferation triggers hypoxia-inducible factor activity (60). Ghosh 
et al recommended that a Mediterranean diet may be important in reducing the risk of cervical cancer (61). In contrast, other researchers argued that folate, vitamin B12, and vitamin B6 may play a role in HPV integration (62).

Limitation of the Study

The limitation of our study included the lack of information on the high-risk behaviors of the spouse since some people would not discuss any instances of drug abuse by women or their spouses.

\section{Conclusions}

Many of the current problems in this society, particularly in women are due to the transition of society from a traditional to a modern model. The incidence of cancer is rising in the world and young women are still the victims of cancer. In addition, the consumption of processed and high-fat foods can make the women of our society more vulnerable to cancer. On the other hand, stress relief and increased interpersonal relationships can reduce the incidence of the disease in cervical cancer patients. Although the role of HPV in cervical cancer is evident, the lifestyle of women with the disease is also effective.

\section{Conflict of Interests}

Authors declare that they have no conflict of interests.

\section{Ethical Issues}

All stages of this study, including the approval and implementation were approved by the Ethics Committee of the Research Deputy of Shahid Beheshti University of Medical Sciences, Tehran, Iran (No. SBMU2.REC134.53).

\section{Financial Support}

The research was funded by Shahid Beheshti University of Medical Sciences Tehran, Iran.

\section{Acknowledgments}

The authors would like to appreciate the cooperation of the Research Deputy of Shahid Beheshti University of Medical Sciences, Tehran, Iran and all women who participated in this research.

\section{References}

1. Siegel R, Ward E, Brawley O, Jemal A. Cancer statistics, 2011: the impact of eliminating socioeconomic and racial disparities on premature cancer deaths. CA Cancer J Clin. 2011;61(4):212-236. doi:10.3322/caac.20121

2. Rasaf MR, Ramezani R, Mehrazma M, Rasaf MR, AsadiLari M. Inequalities in cancer distribution in Tehran; a disaggregated estimation of 2007 incidence by 22 districts. Int J Prev Med. 2012;3(7):483-492.

3. Torre LA, Bray F, Siegel RL, Ferlay J, Lortet-Tieulent J, Jemal A. Global cancer statistics, 2012. CA Cancer J Clin. 2015;65(2):87-108. doi:10.3322/caac. 21262

4. WHO/ICO Information Center of HPV and Cervical Cancer (HPV Information Center). Human Papillomavirus and Related Cancers in the World. Summary Report 2010. Available from: http://www.who.int/hpvcentre/en/. Accessed September 19, 2011.

5. Vistad I, Fosså SD, Dahl AA. A critical review of patientrated quality of life studies of long-term survivors of cervical cancer. Gynecol Oncol. 2006;102(3):563-572. doi:10.1016/j. ygyno.2006.03.050

6. Warnakulasuriya S. Living with oral cancer: epidemiology with particular reference to prevalence and life-style changes that influence survival. Oral Oncol. 2010;46(6):407-410. doi:10.1016/j.oraloncology.2010.02.015

7. Anand P, Kunnumakkara AB, Sundaram C, et al. Cancer is a preventable disease that requires major lifestyle changes. Pharm Res. 2008;25(9):2097-2116. doi:10.1007/s11095008-9661-9

8. Habib SH, Saha S. Burden of non-communicable disease: Global overview. Diabetes Metab Syndr. 2010;4(1):41-47. doi:10.1016/j.dsx.2008.04.005

9. Mohebbi E, Nahvijou A, Hadji M, et al. Iran Cancer Statistics in 2012 and Projection of Cancer Incidence by 2035. Basic Clin Cancer Res. 2017;9(3):3-22.

10. Brotherton JM, Ogilvie GS. Current status of human papillomavirus vaccination. Curr Opin Oncol. 2015;27(5):399-404. doi:10.1097/cco.0000000000000211

11. Bifulco G, De Rosa N, Tornesello ML, et al. Quality of life, lifestyle behavior and employment experience: a comparison between young and midlife survivors of gynecology early stage cancers. Gynecol Oncol. 2012;124(3):444-451. doi:10.1016/j.ygyno.2011.11.033

12. Demark-Wahnefried W, Morey MC, Sloane R, Snyder DC, Cohen HJ. Promoting healthy lifestyles in older cancer survivors to improve health and preserve function. J Am Geriatr Soc. 2009;57 Suppl 2:S262-264. doi:10.1111/j.15325415.2009.02507.x

13. McTiernan A. Mechanisms linking physical activity with cancer. Nat Rev Cancer. 2008;8(3):205-211. doi:10.1038/ nrc2325

14. Williams K, Beeken RJ, Wardle J. Health behaviour advice to cancer patients: the perspective of social network members. Br J Cancer. 2013;108(4):831-835. doi:10.1038/bjc.2013.38

15. Rutledge L, Demark-Wahnefried W. Weight Management and Exercise for Cancer Survivors. Clin J Oncol Nurs. 2016;20(2):129-132. doi:10.1188/16.cjon.129-132

16. McTiernan A, Irwin M, Vongruenigen V. Weight, physical activity, diet, and prognosis in breast and gynecologic cancers. J Clin Oncol. 2010;28(26):4074-4080. doi:10.1200/ jco.2010.27.9752

17. Martin-Moreno JM, Soerjomataram I, Magnusson G. Cancer causes and prevention: a condensed appraisal in Europe in 2008. Eur J Cancer. 2008;44(10):1390-1403. doi:10.1016/j.ejca.2008.02.002

18. Meihan L, Chung-Ngok W. Validation of the psychometric properties of the health-promoting lifestyle profile in a sample of Taiwanese women. Qual Life Res. 2011;20(4):523528. doi:10.1007/s11136-010-9790-6

19. Cangelosi JD Jr, Ranelli E, Markham FS. Who is making lifestyle changes due to preventive health care information? A demographic analysis. Health Mark Q. 2009;26(2):69-86. doi:10.1080/07359680802619776

20. Hankonen N, Kinnunen M, Absetz P, Jallinoja P. Why do people high in self-control eat more healthily? Social 
cognitions as mediators. Ann Behav Med. 2014;47(2):242248. doi:10.1007/s12160-013-9535-1

21. Yadav K, Krishnan A. Changing patterns of diet, physical activity and obesity among urban, rural and slum populations in north India. Obes Rev. 2008;9(5):400-408. doi:10.1111/j.1467-789X.2008.00505.x

22. Saleem M. Lupeol, a novel anti-inflammatory and anticancer dietary triterpene. Cancer Lett. 2009;285(2):109115. doi:10.1016/j.canlet.2009.04.033

23. Enayatrad $M$, Mirzaei $M$, Salehiniya $H$, et al. Trends in incidence of common cancers in Iran. Asian Pacific J Cancer Prev. 2016; 17:38-42. doi: 10.7314/APJCP.2016.17. S3.39

24. Pinar R, Celik R, Bahcecik N. Reliability and construct validity of the Health-Promoting Lifestyle Profile II in an adult Turkish population. Nurs Res. 2009;58(3):184-193. doi:10.1097/NNR.0b013e31819a8248

25. Weng JR, Tsai CH, Kulp SK, Chen CS. Indole-3-carbinol as a chemopreventive and anti-cancer agent. Cancer Lett. 2008;262(2):153-163. doi:10.1016/j.canlet.2008.01.033

26. Walker SN, Hill-Polerecky DM. Psychometric Evaluation of the Health-Promoting Lifestyle Profile II. Omaha: University of Nebraska Medical Centre; 1996.

27. Mohammadi Zeidi I, Pakpour Hajiagha A, Mohammadi Zeidi B. Reliability and validity of Persian version of the health-promoting lifestyle profile. Journal of Mazandaran University of Medical Sciences. 2012;21(1):102-113. [Persian].

28. Misra JS, Srivastava S, Singh U, Srivastava AN. Risk-factors and strategies for control of carcinoma cervix in India: hospital based cytological screening experience of 35 years. Indian J Cancer. 2009;46(2):155-159. doi:10.4103/0019509X.49155

29. Sreedevi A, Javed R, Dinesh A. Epidemiology of cervical cancer with special focus on India. Int J Womens Health. 2015;7:405-414. doi:10.2147/ijwh.s50001

30. Chung SH, Franceschi S, Lambert PF. Estrogen and ERalpha: culprits in cervical cancer? Trends Endocrinol Metab. 2010;21(8):504-511. doi:10.1016/j.tem.2010.03.005

31. Muñoz N, Castellsagué X, de González AB, Gissmann L. Chapter 1: HPV in the etiology of human cancer. Vaccine. 2006;24 Suppl 3:S3/1-10. doi:10.1016/j.vaccine.2006.05.115

32. Anorlu RI. Cervical cancer: the sub-Saharan African perspective. Reprod Health Matters. 2008;16(32):41-49. doi:10.1016/s0968-8080(08)32415-x

33. Appleby P, Beral V, Berrington de Gonzalez A, et al. Carcinoma of the cervix and tobacco smoking: collaborative reanalysis of individual data on 13,541 women with carcinoma of the cervix and 23,017 women without carcinoma of the cervix from 23 epidemiological studies. Int J Cancer. 2006;118(6):1481-1495. doi:10.1002/ijc.21493

34. Gandini S, Botteri E, Iodice S, et al. Tobacco smoking and cancer: a meta-analysis. Int J Cancer. 2008;122(1):155-164. doi:10.1002/ijc. 23033

35. Reiter PL, Katz ML, Young GS, Paskett ED. Predictors of resolution in navigated patients with abnormal cancer screening tests. J Community Support Oncol. 2014;12(12):431-438. doi:10.12788/jcso.0094

36. Benedict C, Kern W, Schmid SM, Schultes B, Born J, Hallschmid M. Early morning rise in hypothalamic- pituitary-adrenal activity: a role for maintaining the brain's energy balance. Psychoneuroendocrinology. 2009;34(3):455-462. doi:10.1016/j.psyneuen.2008.10.010

37. Oran NT, Can HO, Senuzun F, Aylaz RD. Health promotion lifestyle and cancer screening behavior: a survey among academician women. Asian Pac J Cancer Prev. 2008;9(3):515-518.

38. Rohani C, Abedi HA, Omranipour R, Langius-Eklöf A. Health-related quality of life and the predictive role of sense of coherence, spirituality and religious coping in a sample of Iranian women with breast cancer: a prospective study with comparative design. Health Qual Life Outcomes. 2015;13:40. doi:10.1186/s12955-015-0229-1

39. Gouin JP, Glaser R, Malarkey WB, Beversdorf D, KiecoltGlaser J. Chronic stress, daily stressors, and circulating inflammatory markers. Health Psychol. 2012;31(2):264268. doi:10.1037/a0025536

40. Pillay B, Lee SJ, Katona L, Burney S, Avery S. Psychosocial factors predicting survival after allogeneic stem cell transplant. Support Care Cancer. 2014;22(9):2547-2555. doi:10.1007/s00520-014-2239-7

41. Clemmens DA, Knafl K, Lev EL, McCorkle R. Cervical cancer: patterns of long-term survival. Oncol Nurs Forum. 2008;35(6):897-903. doi:10.1188/08.onf.897-903

42. You J, Wang C, Rodriguez L, Wang X, Lu Q. Personality, coping strategies and emotional adjustment among Chinese cancer patients of different ages. Eur J Cancer Care. 2018;27(1):e12781. doi:10.1111/ecc.12781

43. Sisolefsky F, Rana M, Herzberg PY, Gellrich NC, Rana M. Screening for psychological distress: A new approach to identify the patient's psychological needs in a pilot study on oral cancer patients. J Craniomaxillofac Surg. 2017;45(8):1133-1137. doi:10.1016/j.jcms.2017.05.008

44. Kapogiannis A, Tsoli S, Chrousos G. Investigating the Effects of the Progressive Muscle RelaxationGuided Imagery Combination on Patients with Cancer Receiving Chemotherapy Treatment: A Systematic Review of Randomized Controlled Trials. Explore (NY). 2018;14(2):137-143. doi:10.1016/j.explore.2017.10.008

45. Chong Guan N, Mohamed S, Kian Tiah L, Kar Mun T, Sulaiman AH, Zainal NZ. Psychotherapy for cancer patients:A systematic review and metaanalysis. Int J Psychiatry Med. 2016;51(5):414-430. doi:10.1177/0091217416680197

46. Semple CJ, Dunwoody L, George Kernohan W, McCaughan E, Sullivan K. Changes and challenges to patients' lifestyle patterns following treatment for head and neck cancer. J Adv Nurs. 2008;63(1):85-93. doi:10.1111/j.13652648.2008.04698.x

47. Schellekens MPJ, van den Hurk DGM, Prins JB, et al. Mindfulness-based stress reduction added to care as usual for lung cancer patients and/or their partners: A multicentre randomized controlled trial. Psychooncology. 2017;26(12):2118-2126. doi:10.1002/pon.4430

48. Watson M, White C, Lynch A, Mohammed K. Telephonedelivered individual cognitive behavioural therapy for cancer patients: An equivalence randomised trial. Psychooncology. 2017;26(3):301-308. doi:10.1002/ pon. 4338

49. Moghaddam Tabrizi F, Radfar M, Taei Z. Effects of 
supportive-expressive discussion groups on loneliness, hope and quality of life in breast cancer survivors: a randomized control trial. Psychooncology. 2016;25(9):1057-1063. doi:10.1002/pon.4169

50. Moore PM, Rivera Mercado S, Grez Artigues M, Lawrie TA. Communication skills training for healthcare professionals working with people who have cancer. Cochrane Database Syst Rev. 2013(3):Cd003751. doi:10.1002/14651858. CD003751.pub3

51. Owen R, Jeffrey D. Communication: common challenging scenarios in cancer care. Eur J Cancer. 2008;44(8):11631168. doi:10.1016/j.ejca.2008.02.029

52. den Heijer M, Vos J, Seynaeve C, et al. The impact of social and personal resources on psychological distress in women at risk for hereditary breast cancer. Psychooncology. 2012;21(2):153-160. doi:10.1002/pon.1879

53. Ulmer H, Borena W, Rapp K, et al. Serum triglyceride concentrations and cancer risk in a large cohort study in Austria. Br J Cancer. 2009;101(7):1202-1206. doi:10.1038/ sj.bjc. 6605264

54. Cust AE, Kaaks R, Friedenreich $\mathrm{C}$, et al. Metabolic syndrome, plasma lipid, lipoprotein and glucose levels, and endometrial cancer risk in the European Prospective Investigation into Cancer and Nutrition (EPIC). Endocr Relat Cancer. 2007;14(3):755-767. doi:10.1677/erc-07-0132

55. Woodruff TK, Khosla S. New hope for symptom management during natural and iatrogenic menopause transitions. Biol Reprod. 2017;97(2):177-178. doi:10.1093/ biolre/iox079

56. Rossouw JE, Cushman M, Greenland P, et al. Inflammatory, lipid, thrombotic, and genetic markers of coronary heart disease risk in the women's health initiative trials of hormone therapy. Arch Intern Med. 2008;168(20):22452253. doi:10.1001/archinte.168.20.2245

57. Sowers MR, Randolph J Jr, Jannausch M, Lasley B, Jackson E, McConnell D. Levels of sex steroid and cardiovascular disease measures in premenopausal and hormone-treated women at midlife: implications for the "timing hypothesis". Arch Intern Med. 2008;168(19):2146-2153. doi:10.1001/ archinte.168.19.2146

58. Strasak AM, Pfeiffer RM, Brant LJ, et al. Time-dependent association of total serum cholesterol and cancer incidence in a cohort of 172,210 men and women: a prospective 19year follow-up study. Ann Oncol. 2009;20(6):1113-1120. doi:10.1093/annonc/mdn736

59. Kundu JK, Surh YJ. Inflammation: gearing the journey to cancer. Mutat Res. 2008;659(1-2):15-30. doi:10.1016/j. mrrev.2008.03.002

60. Baenke F, Peck B, Miess H, Schulze A. Hooked on fat: the role of lipid synthesis in cancer metabolism and tumour development. Dis Model Mech. 2013;6(6):1353-1363. doi:10.1242/dmm.011338

61. Ghosh C, Baker JA, Moysich KB, Rivera R, Brasure JR, McCann SE. Dietary intakes of selected nutrients and food groups and risk of cervical cancer. Nutr Cancer. 2008;60(3):331-341. doi:10.1080/01635580701861769

62. Chih HJ, Lee AH, Colville L, Binns CW, Xu D. A review of dietary prevention of human papillomavirus-related infection of the cervix and cervical intraepithelial neoplasia. Nutr Cancer. 2013;65(3):317-328. doi:10.1080/01635581.20 13.757630

(c) 2019 The Author (s); This is an open-access article distributed under the terms of the Creative Commons Attribution License (http://creativecommons.org/licenses/by/4.0), which permits unrestricted use, distribution, and reproduction in any medium, provided the original work is properly cited. 